\title{
Dwelling Near in Mountains Farthest Apart: A Conversation
}

\author{
REMMON E. BARBAZA \\ ATENEO DE MANILA UNIVERSITY, PHILIPPINES \\ PALOMA POLO \\ SPANISH VISUAL ARTIST
}

\begin{abstract}
In November 2012, Amsterdam-based Spanish visual artist Paloma Polo came to the Philippines for the initial phase of her project on land use and vulnerability. She was hosted by the Department of Philosophy at the Ateneo de Manila University, with some of whose members she began collaborating, including Remmon E. Barbaza, an associate professor of philosophy who is currently working on an interdisciplinary project on disaster risk management. Polo is currently based in Manila to develop a research project and to work on a film project on the topics mentioned earlier, and is collaborating and teaching as adjunct professor with the Center for International Studies at the University of the Philippines at Diliman, Quezon City. In this conversation, Polo and Barbaza exchange ideas on such topics as interdisciplinary work, art, philosophy, history, human agency, and the necessity behind the creative impulse, in both artistic and intellectual works.
\end{abstract}

Key terms interdisciplinarity, philosophy, art, historiography, microhistory

Budhi: A Journal of Ideas and Culture 17.2 (2013): 149-68. 
B arbaza: I remember quite well the circumstances of our first personal encounter. Perhaps they indicate a few things about our current situation as people involved in the shaping of culture-as artists, intellectuals, or academics. There you found your way to my University here in Manila, one fine day in November last year, with a project of your own, an artistic project on land use and vulnerability. And by some happy coincidence, I was also just about to begin an interdisciplinary research project on disaster risk management. It seems that more and more, we are being asked to cross the boundaries of our disciplines, even as we remain rooted in our own. For, indeed, one can only contribute to an interdisciplinary project if one has grown in one's own discipline.

I see this phenomenon of interdisciplinarity in you: as an artist, you take genuine interest in questions belonging to the social and natural sciences, and, indeed, your own works have been informed by these other disciplines. But if you remember, I told you that I was a bit surprised, maybe even amused, that you came to our University on board one of those tricycles, which are not only notorious pollutants, but also far too noisy and at times may be even dangerous especially for foreigners like you who come to our country for the first time. I remember you yourself were quite surprised why I expressed concern about your safety, telling me it was nothing at all and that you've been in situations far more dangerous than that.

That seems to point to another thing I gathered from you. That in our time, one cannot really be an artist, or an intellectual, without taking risks, without entering into those realms of human existence that might seem to be fraught with danger, perhaps not really because they are dangerous in themselves, but because they are unknown. As you so beautifully saidand that is something I will not forget- "entering the unknown through the unknown."

Polo: Thank you, Remmon, for trusting that my working process can contribute in some way to your interests and fieldwork. One of my greatest challenges and interests is to produce content and thought that can become meaningful to other disciplines beyond the purely artistic. 
The projects I have realized in the past required the collaboration of experts and scholars belonging to a pretty wide range of fields and disciplines. This circumstance has brought me closer to their methodologies. My working process has been enriched by it. However, I always sensed (and here I am generalizing) that the working paths set for academic work tend to be absorbed in their specific disciplinary approach and disengaged from other thinking processes that may relate to the same topic from different angles.

Many contemporary issues are in urgent need of multidisciplinary and cross-cultural analysis. I have come to believe in collaborative work as key to the production of knowledge. And I have tried to integrate this in my practice.

You often tell me I run very near the realm of academic research. Perhaps that is true, but I rather see myself treading on the sides of academic research. As an artist I don't feel a responsibility towards any institution, and so in that sense I can allow myself much more freedom. But, to me, gaining freedom implies building up a new methodology with each project, coherent enough to address the issue at hand meaningfully.

I don't think I told you, but the quote you recall was not my own. I read it in a text written by the Spanish artist Txomin Badiola a long time ago, and it has accompanied me since. What I actually find most beautiful about it is this "by means of the unknown." It is where the risk lies. It is by making up a new thinking scheme, by following a new path of thought, that one arrives to an unknown landscape (in the wider sense of the word). The unknown doesn't necessarily need to be foreign or new; it is rather something that reveals itself in a form that hasn't been conceived before.

Barbaza: There is yet much to be said about multidisciplinary or interdisciplinary research and analysis (now, we even hear of "transdisciplinary" research as a distinct approach). A few months ago, the Sociology Department in my University hosted an international conference precisely on this topic. The keynote speaker, an American sociologist, cautioned against a misunderstanding of interdisciplinary research, one that proceeds from or could lead to a watering down of one's own discipline. 
He said that one should first be solid in one's discipline, and to keep growing in it. I think he was referring to a tendency, especially among young researchers, to get excited about getting involved in interdisciplinary work right away, which I think goes hand in hand with an unexamined desire to be "relevant" (what a dreadful word that is!), without first building one's foundations in one's own discipline. The point I think is that, only those who are already rooted in their own disciplines can truly and productively engage in interdisciplinary work.

I myself am learning in this regard, and groping my way through it. For example, a few years ago I joined an interdisciplinary research group working on the topic of managing water for a sustainable future. It was my first foray into collaborative work with scholars from other disciplines, including those from the natural and the social sciences. Initially I felt that in our discussions I should sound scientific before natural and social scientists, used as they were to empirical research and the scientific method. But later on, I realized that I was starting on the wrong foot, since I sensed that my collaborators were actually expecting philosophical insights from me, using my own language, and my own method. I realized I was invited to join that group, not to sound like everyone else, but precisely to bring to language the insights that developed from within my engagement in my own discipline.

That is why I see you as a very good example of how to go about collaborative work with academics and scholars from various disciplines. You often clarified to your collaborators that yours is an artistic project, that you are primarily an artist wanting to express your insights artistically, even as you need the help of various experts in the social and natural sciences, as well as actors in the political sphere. I sensed in you a healthy self-awareness, even confidence, about who you are and what you do as an artist, even as you keep yourself totally open to the insights of others from very diverse disciplines. I do not sense insecurity in you, but only a genuine openness and desire to learn from and be enriched by others.

Polo: I agree with you. I find that if we look for a solid and productive evolution of multidisciplinary work, it is appropriate to raise awareness of the dangers it may entail. However, from my perspective, building one's 
foundations in one's discipline demands openness to inputs from others. I believe it has always been like this, though the academic world has drawn stronger and more definite boundaries limiting each field of work.

The desire or the need to go beyond a discipline comes from a critical conscience of the parameters set in such domain. I would say that, when one is certain about what the work is lacking, why a method should be redesigned, what became obsolete, where to head, from what position one is asking, etc., an attempt to cross disciplines is justified and may lead to interesting results. This has occurred so often throughout past decades that multidisciplinarity has become a trend. I don't really have a problem with that, but I have observed it can be erratic, when it is, for instance, imposed on a working group or a study, and the researchers involved haven't identified a need for it beforehand; or when a study throws itself into it so enthusiastically, that the need to establish interdisciplinary connections surpasses a real progress content-wise. Then, the connections established risk being purely anecdotal. I have seen the latter occurring in art very often.

Throughout last century, art has experienced very significant and relevant twists. Artists have critically reflected on art as a discipline, questioning one by one all qualities that historically were attributed to artmaking and the artistic products. While remaining a discipline, art has successfully caught up with the world re-signifying the meaning of the artistic gesture in contemporary life. Successive currents have examined the qualities that constitute an art object, the tools or means used to produce it, the nature of the artistic work, what or who authorizes whatever becomes art, how the viewer influences the composition of the work and how the work defines the viewer, the container of art, the presentation of the work, the site specificity of the art object, the role of the organisms and institutions hosting artistic work, the political potential and political limitations of art, the political role of art in society, etc. In this sense, it could be said that the art produced during last decades has been preoccupied with its disciplinary status, and the production of work has been determined by this concern. 
We are living in interesting times for art, perhaps because we are generally living in interesting times, and art reflects and responds to a given historical context. Art production is experiencing major changes, even when we don't have a clear awareness yet of how these changes are happening or operating. Unfortunately, not all changes are positive; the market has absorbed art to such an extent that the majority of its critical inquiries are subject to the art industry's ruling. Still, a little space is spared or can be found to develop an activity that functions under different premises.

Art has gained strength and awareness in what concerns its disciplinary nature, which gives way to new possibilities of thinking the art practice and its role nowadays.

Has philosophy as a discipline undergone a similar process?

Barbaza: I cannot assume that all philosophers consider the awareness of the history of philosophy as essential, indeed a sine qua non, to philosophizing itself. But while I myself consider that as essential, I am afraid that I have not done enough work in this regard.

But allow me to point to a number of things, albeit at random.

First, it is generally known, at least within the academe, that when philosophy became a science (in the academic sense, that is), we saw it branching out into other inquiries (we might say disciplines), beginning from the time of Plato and Aristotle. These disciplines left philosophy behind (i.e., in its more original, "pure" form, which is usually associated with the pre-Socratics). Several centuries later, not only was philosophy left behind, but also, quite ironically, discredited and ridiculed as amounting to nothing but hot air.

But I do believe that fundamentally, philosophy cannot be understood as simply one discipline among many others, or that philosophy itself has "branches." There are at least two reasons for this. First, there are no basic terms, methods, and principles universally agreed upon in doing philosophy. These are always put to question. Second, there is no common definition of philosophy to begin with. These two of course are connected. One might say that the same is true with any other discipline, that its basic 
terms and premises are always questionable, but I guess the difference is that it is more radically so in philosophy. Just imagine if physics gets bogged down with the question of what space really is, whether it exists or not, and if so in what sense. If it did not simply set that question aside, it would not be able to pursue its research. The medical doctor must not get involved in asking what the nature of the human body really is, what its relation is to the mind (or the soul), etc., while on the operating table, lest the patient dies. If she does so in her spare time (of course she can and I would even hope she does), then she does so, no longer as one doing medicine, but as one engaging in a philosophical question.

That is why I think Jaspers was correct in saying that, in contrast to science, there is no progress in philosophy. But neither is there regress. And as Heidegger, for his part, says, there is only a circling within the circle, or that the point is not to solve the riddle, but to see it. For this reason we can study Heraclitus or Parmenides over and over again, and see something new each time. Heraclitus is not and will never be outdated. It might even be truer to say that we haven't caught up with him yet.

I am pointing this out because, again as Heidegger says, when philosophy engages the public (or other disciplines), it always seems to start on the wrong foot. It is oftentimes an awkward situation. Perhaps that is a problem that is peculiar to philosophy. But as I would like to point out later, this is something that philosophy shares with art or poetry, insofar as all art is poetry.

But having said this, I think that, perhaps without deliberately doing or meaning it, philosophers did engage in what we might now call interdisciplinary research. One thinks of the likes of Nietzsche, who seems to move across disciplines, like philosophy, history, literature, music, psychoanalysis; Marx, with his works covering philosophy, economics, history, political science; those associated with the Frankfurt School, and their inquiries using sociology, psychoanalysis, political science, and even phenomenology.

Nowadays we find that to be more and more the case with philosophy practitioners in general. 
But I would like to focus now on what you said that I think is very important and incisive, and something that should guide those finding themselves involved in interdisciplinary or transdisciplinary research. In effect you are saying, if I understood you correctly, that our work must be motivated by a real need. Without this real need, interdisciplinary work can become a farce; it can degenerate into something superficial or contrived. When there is a real need, however, then this need itself will tell us where to go, whom to approach, with which disciplines we must engage, etc. As you said so well, this need can be in the form of an awareness of what is lacking in one's work, why and how one's method is to be redesigned, how to redirect one's inquiries, etc. I would say that this real need is the same as a real question, which often means a burning question that haunts us, and whose necessity makes us say, I simply cannot not do it.

I suppose we can say that every inquiry, for that matter, must proceed from a real necessity. An inner necessity. Whether our readers or viewers, or the public in general, will see the same necessity, however, is another question. But we must first be true to ourselves, that first of all we are responding to an inner necessity.

Polo: From Marc Bloch's, The Historian's Craft: "Man spends his time devising techniques of which he afterwards remains a more or less willing prisoner."

Your response has brought historiography to my mind. I am very interested in the nature of history as a discipline, its purpose and its methods, precisely because it illustrates more clearly the dilemmas you describe. Unlike art or philosophy, history exists to analyze a specific content: all the different social processes that move and transform the world we acknowledge. Historiography strives to decipher how the object of history can be successfully attained, there is much to learn from its critical production.

Below I would like to transcribe another passage from Bloch, which, to me, introduces a political dimension to the issues you raise: "Is it suggested that the documents have already inserted a preliminary screen between past 
and present? Certainly, they often eliminate at random. On the other hand they almost never organize the subject-matter according to the demands of an intelligence that seeks to know."

Barbaza: It seems to me that one way or another our conversation will take us to the question of history. In turn, confronting the question of history necessarily brings us to the political realm insofar as politics is the realm of human action, which itself is commonly assumed to be that which moves history — at least history as it is traditionally understood.

But then this ultimately forces upon us the seemingly intractable problem of human agency vis-à-vis history. It is commonly taken for granted that history is shaped by human action (in the realm of the political), and this in turn is widely assumed to be the action of the victorious. What we are often told is the history of victors, of the primary actors in history. History is victorious history. It marches onward, at such a pace set by the victors. History progresses as victories are achieved.

Now, original thinkers such as Nietzsche (with his genealogical analysis) and, closer to home, Reynaldo Ileto (with his "history from below") have done much to challenge our traditional understanding of history. Others who entertain further suspicion ask whether it is closer to truth to view ourselves not so much as agents, but rather as "victims of history." One can rephrase the passage you quote from Bloch and say that "history" is a technique we devise, supposedly to help us be in control of events, but which itself later imprisons us. Are we victims and prisoners of our own devices? Or is history something that transcends all framing and devising?

What indeed is history? The passages you just quoted seem to point to this riddle, for indeed history will in the end point to a riddle, is itself a riddle.

It might help here to consider the distinction that Heidegger makes between history as historiography (Historie) and history as historical event (Geschichte). The German language allows us to hear this distinction perhaps more easily. Historiography attempts to capture what happens in history. But in the end, history is an Unumgängliches, it is something not to be gotten 
around. With historiography we try to frame what happens in history, as the passages you quote seem to suggest, but only to realize later that we need to break free from those parameters or frames that we set, and then we try to interpret history anew. There is never really a last word in history (as Geschichte). For it remains to be something that points to das Unumgängliche, that which is not to be gotten around.

Your recent artistic works, about which you spoke with us at the Ateneo de Manila, notably "Action at a Distance," "The Path of Totality," "Enough Redundancy in the System," and now your project on land use and vulnerability, seem to me-knowingly or unknowingly on your partto betray a sense of that which is not to be gotten around, whether in the realm of scientific expeditions (where the human being as scientist, in his attempt to control and predict, in the end still has to contend with something that is ultimately beyond his control) or in the realm of the political (where traditional politicians and power brokers impose, in a rather violent way, their idea of progress on a people who have long lived in the land that is now under threat).

To me it is certainly very significant that Catalina Lozano, in describing your work "Action at a Distance," says the following: "Without getting caught up in a documentary or aestheticizing language, images and sound seek to capture a situation which, with all its vertices, we cannot fully retain."

I cannot help but think that the "situation that we cannot fully retain" points to history as that which cannot be gotten around.

Perhaps this brings us back to the beginning of our conversation, which also points to how our first meeting took place. We do have our plans and our projects, but at bottom, more fundamentally that is, you and I are merely responding to something that is summoning us. And what summons us is beyond mere human planning and calculations.

What is it that the artist responds to when she is moved to produce a work of art? What is it that the thinker heeds when something provokes her to think? 
Polo: You have pointed out above several concerns underpinning my artistic practice.

There have been other attempts to rethink or resolve this riddle of history, as you call it, that are worth noting. My interest in history and, subsequently, historiography has driven me closer to the thinking and methods applied by microhistory, an Italian-born and rather more experimental historiographical method developed in the 70s that soon influenced the rest of European and North-American historians.

Unfortunately, this current was later absorbed and adulterated by the orthodoxy of the historical academic practice, becoming a trend that has even been condemned by the leading advocates of these studies.

One of the most relevant exponents and initiators of microhistory is Carlo Ginzburg, whom I had the pleasure of visiting and interviewing in Bologna a couple of years ago.

The microhistorical approach would begin modifying the scale of observation and looking at the exceptional case or event, that which is statistically infrequent. An anomalous circumstance or individual promptly refers to a rule or a pattern, generally imposed by dominant historical discourses, but it can also widen the scope of observation and amount to the analysis of a determined time frame or situation.

Microhistory would look at a specific small point, with the conviction that one particular theme is a gateway to another of general character. Thus, an exceptional document or event could be more revealing than those acknowledged by generalists' narratives.

Ginzburg analyzed the function of the "indicial paradigm," which proposes a historical research based on the compilation and morphologic interconnection of traces, threads, or symptoms:

The indicial paradigm places this complex dialectic between norm, or law, or trend, or general processes, and on the other hand the case, or reality, or the manifestation, or the specific and strictly individual and unique expression of said general dimensions in the center of its attention. And so not only does it simultaneously exceed the limits of the narrow historicist position, and the possible misinterpretations and distortions of 
"generalist" or "universalist" positions, but it also restates in new terms the important dialectic between what is general and particular in the story. (In Carlos Aguirre Rojas, Indicios, Lecturas Indiciarias, Estrategia Indiciaria y Saberes Populares.)

To me, microhistory seems to be a more sensible and fair approach to historical awareness.

Barbaza: Given the dominant background of a history of victors, I am all too inclined to believe in what you point out, that what is anomalous or exceptional can turn out to be what is more revealing. And this means that an "anomaly" is only an anomaly, and an "exception" only an exception, from the point of view of the dominant history. It would be like saying that, yes, an artist or a thinker may be standing on his or her head indeed, but only from the point of view of someone who turned things upside down to begin with. Iron bars may have physically restrained Mandela for twenty-six or twenty-seven years, or a house arrest may have physically neutralized Aung San Suu Kyi for nearly fifteen years, for example, but the ones who stand outside are the ones who really remain imprisoned.

And yet when we speak of "microhistory," we are opening ourselves not even just to great women and men like Aung San Suu Kyi and Mandela, but also to those who will remain unknown, but who nonetheless move history just as strongly and as decisively. Again, this brings to mind Ileto's way of doing history, namely, "history from below."

Polo: Throughout the course of my last project, Apparent Position, I attempted to connect these theories with the changing scientific methodologies of the physicist. I didn't really succeed at this task, but this effort triggered the formalization of the different works I produced.

Apparent Position stemmed from a research project I had pursued, for a long time, on the history of solar eclipse expeditions undertaken by several western powers throughout the 19th and beginning of the 20th centuries, where I explored the relationship these scientific quests had with the expansion of Western markets and economies, namely the imperial and colonialist expansion. 
There always exists something that "can't be gotten around" or that remains "not to be gotten around" in the series of events, contexts, and circumstances I examine. In this project, I was caught up and, at the same time, repelled by seeing scientific knowledge production running hand in hand with violently imposed forms of domination and oppression. Even when we are well aware of such implications, the depth of the impression left in me reached the bottom of the abyss when these assumptions stopped being abstract or general correlations to become specific actions, objects, texts, photographs, results, routes, plans, sentences, or words. I would be exploring such traces in materials officially held by archives and curated in acknowledgment of the remarkable ideas and, indeed, beautiful propositions they expressed, but the different formats featuring such documents denoted an absolute disdain of the political conditions that facilitated and promoted their existence.

I just happened to read these lines by Alain Badiou in The Communist Hypothesis: "The Idea is a historical anchoring of everything elusive, slippery and evanescent in the becoming of a truth."

I would say that the word "Idea" may also be replaced in this sentence by "artistic expression."

Now, my project revolved around a solar eclipse expedition to the island of Príncipe (located on the west coast of Africa) during the summer of 1919. The experiment realized during the observation of the eclipse of May 29, 1919 was the first to validate Einstein's general theory of relativity for the majority of the scientific community. It had a broad media impact and projected strong social and political implications.

Einstein's theory would rebut the absolute conception of space and time established by Newton in his treatise Philosophiae Naturalis Principia Mathematica (1687), in which mathematical laws were introduced to describe all forms of movement that had governed the conception of the universe for the past 200 years.

The expedition was directed by the Observatory of Cambridge and led by the renowned astronomer Sir Arthur Eddington. The task of the astronomers was to photograph the apparent position of a constellation of 
stars, the Hyades, conveniently located behind the Sun at the time of the eclipse.

Einstein had completed three physically observable effects that would verify his theory. One is the deviation of the path of light passing through a powerful gravitational field. Only the mass of the Sun provided a gravitational field strong enough to provoke a degree of deviation sufficiently significant as to be captured by the photographic technology available at the time.

The concealment of the Sun's brightness during the eclipse would allow the astronomers to observe the Hyades. But the situation of those stars with respect to the Sun as seen from the Earth was not their actual position; they appeared to be displaced with respect to their real location due to the effect of the Sun's gravitational field on the trajectory of the light they projected. Einstein had calculated the exact degree of displacement.

Barbaza: You have been acutely attentive then to this play between concealment and unconcealment, between what is obvious and what is only apparent. This "apparent position," apparently was more than just apparent, but in fact was revealing in many ways that were quite profound, and happily even granted you a most apt title for your work. I honestly find that thoroughly fascinating.

Polo: Exactly. I often find a poetic and conceptual depth in scientific terminology; it very easily accords meaningfully with the social and political context of its conception. The apparent position of the stars became a metaphor that guided my inquiries in the historical circumstances of this experiment. Moreover, and on more generalists' accounts of this event, it was interesting to read how society would react to the changes that notions of space or time were undergoing. No independent or absolute properties could be attributed to space and time any longer. Simultaneity was not an invariable concept.

Einstein's work and theory was featured in all newspapers worldwide. I presume it made a good item with which to draw away the attention of the readers from war. With the general theory of relativity, Einstein would seek 
to formulate natural laws in a way that their form would be identical for coordinate systems of any kind of movement. That is to say, the expression of physical laws would be entirely independent from the observer's coordinates.

However, Einstein's success misled many authors to interpret his work in a way that would privilege speculation over empiricism, to which he strongly objected: "But I find that this development teaches something different that is almost the opposite, namely, that in order to be reliable, a theory must be built upon generalizable facts."

Space and time had changing properties; time could dilate and space was warped. Matter and geometry would be defined by a metric element in specific coordinates, reference systems would vary, but they must satisfy Einstein's equations following a model universe that conforms to the laws of general relativity.

In a similar way, microhistory argued that a singular and anomalous point in history would subsequently refer to the norm and general definitions of its times and, since this relation would not work inversely, narrowing the scale of observation to study the singularity of an account would provide a richer and fuller understanding of a given situation.

This analogy would never be endorsed by scientists from any field, but this "license" can be justified if it serves as a tool to express meaningfully my point.

Barbaza: And for some reason, as you are explaining a segment of the history of science (in a way that indicates at the same time both a philosophy of history as well as of science), what ho Skoteinos- "The Obscure One" - said more than two thousand years ago seems to come to life again, and like him we can say it tongue-in-cheek (but of course on a different level with dead seriousness), namely, that "the sun is the size of the human foot." But is that a mere metaphor that Heraclitus uttered? Curiously, however, as you yourself said, it is precisely a metaphor that guided your inquiries. From a narrow and strict scientific point of view, this is of course a scandal. How can a metaphor guide any inquiry, let alone scientific inquiries! 
Polo: When I refer to "a metaphor I am putting at work," that points to my artistic position, gesture, or creativity — an attempt to relate given notions, structures and specific areas or contexts in a constructive and productive way for the analysis of a historical event.

Einstein was a patent clerk before he devoted himself to science. But in those early days, he was already developing the special theory of relativity. His method consisted in "thought experiments"; he would imagine and visualize different fictional situations in order to reason what would occur in each case, compare them, and draw conclusions. Only the imagination allowed the creation of the necessary conditions for the experiments. This method turned out to be very efficient, producing the foundations of relativity.

I mentioned above the social and popular projection of this experiment and expedition. There were also political repercussions and circumstances that, for instance, decided the location of the observation. Príncipe island was a Portuguese colony at the time. The islands Sao Tomé and Príncipe happened to be located within the Path of Totality (or area of total darkness) during the 1919 solar eclipse, making them a perfect location for the observation.

The alliance between Britain and Portugal during World War I seemed to be favorable enough to facilitate an agreement between both countries in order to provide the infrastructure required to carry out an English expedition of such nature. Thus, the colonial administration in the island of Príncipe welcomed and hosted Eddington's expedition.

It is known that Eddington was a Quaker with profound religious convictions, and so were the English Cadbury brothers, whose company's cocoa supply came mainly from Sao Tomé and Príncipe at the time. The exploited labor in the islands had reached a level of productivity that placed them as world leaders of cocoa production.

In 1905, a few years before the expedition took place, these islands became an international focus of controversy due to the protracted use of a slave work force in the plantations. The appalling working conditions in colonial Africa were unveiled by Henri Nevinson's book A Modern Slavery. 
Commissioned by Harper's Magazine, Nevinson had followed the slave routes in Africa and witnessed the outrageous violence and abuse inflicted on the workers of the plantations. Far from being abolished as a result of the 1858 Portuguese decree, slavery seemed to be at its peak. Productivity in Sao Tomé and Príncipe was not weakened by a life expectancy of five years amongst the slaves, as the strengthened slave trade made them easily replaceable.

The Cadbury brothers, well known for their commitment with the antislavery movement and for the promotion of labor ethics, took some years before deciding to shift their supply sources away from Sao Tomé and Príncipe in an effort to stop the polemic and public accusations.

For obvious reasons, the public repercussion of this historical event is broad. The literary production around this topic ranges from scientific publications, journalistic essays, historical studies, literary adaptations; even the letters written by Eddington during this journey can be found at the Trinity College in Cambridge.

I immersed myself in all these materials throughout the development of the project. Of all accounts and narrations, only one researcher-Gisa Weszkalnys-who actually had stumbled upon the topic by chance, pointed out the absence of a reference to what ought to be an ethical dilemma for a personality like Eddington.

Eddington never referred to the social conflicts taking place in Príncipe, even when he must have gone to their very core: the experiment was prepared and observed from Roca Sundy, one of the largest plantations of the island. Further historical accounts rarely mention those circumstances.

Now we arrive at the Geschichte, a term I would have liked to be familiar with when I was doing this project. Being in this Geschichte, all the physical concepts developed for the theory of general relativity began to seem applicable metaphorically to a critical analysis of this event.

Barbaza: Geschichte, as I understand it, is what happens beyond (or despite?) all human calculations and intentions combined. We have need of course for calculations and planning, that should be clear. What Heidegger, I think, was pointing to was not calculation per se, but a kind of thinking 
that is predominantly calculative. Indeed often we must weigh and plan and measure and calculate, but we must leave room for surrender. Surrender before what? Before that which cannot be gotten around, surrender before what ultimately is a gift.

I would now like to dwell on a particular aspect of what you have shared with me so far. I am fascinated by the way your artistic productions are informed by a critical historical awareness, and a recognition that, in the end, everything that we do-in everyday life, but also science, art, philosophy_constitutes a social act. Specifically, a political act. Hence your sensitivity to "violent impositions of forms of domination and oppression."

To the extent that a scientific project, an artistic production, or a philosophical discourse is accomplished in freedom-in its negative but more so in its positive sense-then each of them participates in the work of liberation, and liberation is clearly a political act. Sure, there is a personal, individual aspect to liberation. We can always speak of inner, personal liberation, and that is of course good and important. But we will be deemed blind if we were to ignore the unavoidable social, political dimension of liberation. Aristotle himself said that humans are born to be citizens, and that we are political animals. Even the decision not to have anything to do with the social community, which might appear totally harmless, is itself a social, political act with actual social, political consequences.

The commitment underlying acts of liberation need not be based on ideological dogmatism or fundamentalism, and in fact is compatible with the humble recognition of "that which is not to be gotten around." As you say, we are moving on slippery ground, and seeking something that will always remain elusive. Real power lies in this commitment to liberation, and unmasks false power that has no real substance, for it only has an empty self that seeks to dominate and oppress others. Badiou speaks of "the incommensurable distance between philosophy and power." Given the context of that utterance he was speaking only of philosophy, but he could as well have replaced philosophy with art, and spoken of the incommensurable distance between true and false power. 
Borrowing the words of Hölderlin, Heidegger said that the thinker and the poet "dwell near in mountains farthest apart." Insofar as all art is poetry, the artist is a poet. You and I perhaps indeed dwell in mountains farthest apart, but something grants us nearness. Could this be the recognition of "that which is not to be gotten around," of something that will always remain slippery and elusive? Could it be the commitment to the work of liberation?

Neither you nor I know where our destinies will lead us as we continue with our philosophical and artistic practices. We hold no certainty, nothing can be predicted or planned ahead, but we can make ourselves ready for whatever is to come and whatever will make itself manifest before us. Whatever good thing we intimate before us, we know not what it is. In the words of Chesterton, all we can say is that "it is a track of feet in the snow/ It is a lantern showing a path/ It is a door set open."

We are humbled enough by the granting of hints along the way, of traces here and there, of gentle intimations, and the slightest of illuminations.

Polo: I find it very appropriate now to recall another metaphor that has accompanied me for a long time: the eclipse.

Eclipses were mainly observed because the comprehension and visualization of solar prominences or other astronomical phenomena required a state of darkness, which would be created by the concealment of sunlight. Obscurity was the only way to access the data and therefore produce scientific conclusions and thought.

Carlo Ginzburg refers to this "being in darkness" as a metaphor to express the task of the historian, which may be applied to that of the artist, the philosopher, or the thinker in general. He would claim that a historian's endeavor was like that of a person's movement in the darkness of a room: feeling the objects around to guess how the space is in order to guide her way.

Barbaza: Obscurity. Being in darkness. Groping as we try to find our way, and following it. Darkness is not an excuse for us not to hear a summons within. We cannot really turn our backs to the inner necessity 
that bids us continue treading our path. We cannot really hide from this necessity. Thus says "the Obscure One": to mê dunon pote pôs an tis lathoi. How can one hide from that which never sets? 